\title{
LAS PEREGRINACIONES DEL REINO DE DINAMARCA A SANTIAGO DE COMPOSTELA
}

\author{
POR
}

\author{
VICENTE ALMAZÁN
}

University of Wisconsin (Oshkosh)

\section{RESUMEN}

El autor trata de demostrar que Ia peregrinación jacobea de Dinamarca fue tan importante y activa como en los otros países escandinavos, sobre todo teniendo en cuenta la densidad de población que es considerablemente más reducida. Analiza la peregrinación jacobea en su triple aspecto histórico, artísticocultural y literario.

\begin{abstract}
The author tries of demonstrating that the jacobeo pilgrimage of Denmark was so important and active as in the others Scandinavian countries, above all taking account the density of population that it is considerably more reduced. Analyzes the jacobeo pilgrimage in his historical, artistic, cultural and literary aspects.
\end{abstract}

Desde la publicación de Las peregrinaciones a Santiago de Compostela de Luis Vázquez de Parga, José María Lacarra y Juan Uría Riu en 1948, disponemos de un valiosísimo documento y amplia fuente de un tema que afecta la historia de la Iglesia en España, y también la de la cultura, de la literatura y del arte no sólo de España, sino de toda Europa.

En los últimos veinte años investigadores españoles y extranjeros en número creciente han ido dedicando numerosos estudios que demuestran que la peregrinación jacobea ya no es un fenómeno limitado al llamdo «camino fran-

$I^{\text {er }}$ Congreso de Historia de la Iglesia Hisparia Sacra 51 (1999) 
cés» de España. En mayor o menor escala este fenómeno comprende aspectos históricos, artísticos, sociales, arqueológicos, literarios y linguísticos de los países vecinos, Portugal y Francia. Si estudiamos particularmente la Edad Media podremos además observar que en lugares tan lejanos y marginados geográficamente como Finlandia, Islandia o las Islas Feroé, el culto al apóstol Santiago fue muy intenso desde el siglo $\mathrm{X}$ hasta el advenimiento de la Reforma.

En esta comunicación trataré de demostrar que la peregrinación jacobea de estos países, y aquí me referiré particularmente al reino de Dinamarca, fue tan extendida como en los otros países, sobre todo si tenemos en cuenta la densidad de población que es aquí considerablemente más reducida.

El Cristianismo llega a Dinamarca, según nos dice la piedra rúnica de Je1ling en Jutlandia, poco antes del 986. Empieza a extenderse en dirección opuesta a lo que ocurrió en España. En nuestro país el Cristianismo hace sus primeros adeptos entre las clases más bajas de la sociedad: esclavos, soldados, etc. En Dinamarca, por el contrario, empieza por las capas más altas: el rey y la nobleza.

Las primeras iglesias danesas datan del 850 (Hedeby) y del 860 (Ribe). Al mismo tiempo que la doctrina cristiana, surge el culto a mártires y santos. El obispo Adán de Bremen escribe en su Gesta Hammaburgensis ecclesia pontificum (Libro III, cap. 67), que cuando el célebre obispo danés Adalberto murió en 1072, dej6 entre sus posesiones la reliquia de una mano del apóstol Santiago que le había regalado el obispo Vitale de Venecia. Además de esta importante reliquia, sabemos por los inventarios de algunas iglesias danesas de la primera mitad del siglo XVI que se encontraban varias reliquias de Santiago'. Además de estos encontramos otros ejemplos en los que se menciona a Santiago sin determinar de qué Santiago se trata (Mayor o Menor).

Las reliquias dieron origen a muchos centros de peregrinación. En Dinamarca, como en la mayor parte de otros países, encontramos dos tipos de peregrinaciones: a lugares dentro del reino de Dinamarca, y otros a santuarios situados más allá de las fronteras nacionales. Según un trabajo de Christoph Daxelmüller y Marie-Louise Thomsen ${ }^{2}$ había en Dinamarca 47 centros de peregrinación, varios de los cuales tenían como centro santos populares no canonizados pero cuya veneración estaba muy extendida por el pueblo.

Prácticamente al mismo tiempo los daneses comenzaron a peregrinar a santuarios extranjeros, algunos de ellos situados a más de mil kilometros de

1 Scriptores Renum Danicanum Medii AEvi. Copenhague, VIII (1834) 262, 272, 274, 276, 277 , $281,286,288,292,294,298$ y 450.

2 «Mittelalterliches Wahlfahrtswesen in Dänemark», Jahrbuch für Volkskunde (WïrwburgInnsbrucj) 1978, 155-204.

$I^{\text {er }}$ Congreso de Historia de la Iglesia

Hispania Sacra 51 (1999) 
Dinamarca. Esperaban encontrar allí alivio a sus males, cumplir un voto, resolver un problema personal, que se les perdonara un castigo en el que habían incurrido, reparar el mal hecho a otra persona, descubrir el sentido de la vida, buscar una aventura o por muchas otras razones difíciles en muchos casos de explicar. Habrá que distinguir varias categorías entre los peregrinos que desde Dinamarca se aventuraban hasta la lejana Galicia, tanto por tierra como por mar, viaje que duraba en su totalidad de dos a cuatro meses.

Los primeros peregrinos conocidos pertenecían generalmente a las altas esferas de la sociedad: reyes, nobles, clérigos y personajes de alto rango que emprendían el viaje acompañados de numeroso séquito. Estas peregrinaciones de los siglos XI, XII y XIII empezaban por lo general en la primavera con el fin de evitar las nieves y los fríos severos frecuentes entre Dinamarca y Galicia.

Establecer el itinerario de los peregrinos daneses hasta la lejana Galicia es un problema difícil de determinar con exactitud debido a la falta de fuentes precisas. Algunas veces poseemos una información parcial que nos orientará del itinerario seguido en algunos tramos, dejando otros a conjeturas y suposiciones más o menos exactas.

Los primeros itinerarios de peregrinos escandinavos conocidos son islandeses, y por consiguiente marítimos. El primer itinerario conocido del norte europeo fue escrito por Nicolás Bergsson, monje benedictino del monasterio de Pverá, en el extremo norte de Islandia, entre 1154 y 1159. Poco después aparece otro itinerario, enteramente marítimo, en un escolio de un manuscrito de la obra de Adán de Bremen ${ }^{3}$. Según este escolio, el itinerario de esta peregrinación empezaba en el antiguo puerto de Ribe, en la costa occidental de Jutlandia. De aquí se seguía a Zwijn y Prawle, en la costa SO de Inglaterra. De aquí a Saint-Matthieu en Bretaña, y finalmente de Saint-Matthieu a La Coruña «iuxta Sanctum Iacobum Compostela». Después de este pequeño desvío terrestre, continuaba por Lisboa y el Mediterráneo hasta Tierra Santa.

En cuanto a los itinerarios terrestres, salidos ya de Dinamarca, el peregrino seguía los mismos caminos que los peregrinos alemanes y franceses. En Dinamarca existía también un camino de peregrinos bien documentado, llamado Harvej (literalmente "camino del gentío, de la tropa», que desde el extremo norte de la península de Jutlandia seguía hasta un terraplén o muralla (Dannevirke) en el extremo sur. Desde la época de los vikingos (800-1000) este cami no constituía la principal via de comunicación entre los países nórdicos y el continente europeo. En el norte de este camino se encuentra la ciudad de Viborg, a la que el peregrino entraba por «la Puerta de Santiago», y atravesaba la ciudad por lo que todavía hoy lleva el nombre de «calle de Santiago», pasando

3 Scriptores Rerum Germanicarum, XVI, p. 340. 
por una iglesia de Santiago. Junto a este camino se encuentran $\longrightarrow$ encontraban - varias capillas o iglesias dedicadas a Santiago: Skagen, Viborg, Horsens, Varde, Genner, Flensborg, ØIsby, Søderbrarup, Svansted, Moldenit y Slesvig, es decir la mitad de las conocidas en el antiguo reino de Dinamarca. También en Søvind, no lejos de este camino, hay una fuente curativa llamada «fuente de Santiago».

Aunque este camino es el más documentado en la literatura danesa, había otros que atravesaban la isla de Jutlandia o la de Fionia para de aquí ir por mar a los puertos alemanes de Lübeck o Stralsund. A partir del siglo X la liturgia introdujo oraciones especiales para el peregrino, acompañadas en muchas ocasiones de la entrega de símbolos. Un hombre se convertía en peregrino según un rito semejante al que lo admitía a la orden de caballería. En Escandinavia este rito fue descrito detalladamente por Olaus Magnus (1490-1557) en su Historia de gentibus septentrionalibus, escrita en 1555. El capítulo de esta ceremonia concluye con estas palabras: «Pido seriamente a todos los lectores sinceros que leen con modestia estas palabras que recuerden que la vida del hombre es una lucha y una peregrinación».

El primer escandinavo cristiano que llega a tierras hispanas es el rey noruego Sigurd, el peregrino a Jerusalén que tuvo lugar en 1108. Algo más tarde, en 1151, tuvo lugar la expedición de Noruega a Galicia de Reginaldo III el santo, de las Islas Orcadas. La Orkneyinga Saga (caps. 86 y 87) nos describe con detalle su estancia en Galicia ${ }^{4}$.

Aparte de los viages del rey Sigurd y del conde Reginaldo sólo tenemos noticia de dos peregrinos daneses anteriores al siglo XIII. El historiador danés Peter Friderich Suhm, en su monumental Historie af Danmark de principios del siglo pasado, nos habla de un clérigo llamado Absalón que «había estado en Santiago de Galicia allá por el año 1181» durante el reinado de Valdemar $\mathrm{I}^{5}$.

Hacia el año 1190 tuvo lugar otra peregrinación danesa a Santiago de Compostela. Se trata de un caso más bien macabro. Un muchacho de siete años mató a otro de un hachazo a orillas del río Eider que durante siglos ha formado la frontera entre el reino de Dinamarca y el Imperio alemán. Aunque el muchacho escondió la cabeza y el cuerpo de su víctima, el crimen fue descubierto y el muchacho condenado a muerte. Winido, su padre, hizo entonces una peregrinación a Jerusalén y más tarde, esta vez acompañado de su esposa, otra peregrinación expiatoria a Santiago de Compostela ${ }^{6}$.

4 Esta saga se encuentra en las pp. 238-277 del tomo III de la edición de B. Ađalbjarnarson, Reykjavík, 1951.

5 Copenhague, 1800 , t. VII, p. 631.

6 Scriptores Rerum Danicarum, V, pp. 372-374.

$I^{\text {tr }}$ Congreso de Historia de la Iglesia

Hispania Sacra 51 (1999) 
Es muy probable que fuera antes de terminar el siglo XII cuando tuvo lugar la peregrinación compostelana de un habitante de Randers, en el norte de Jutlandia. En la biografía de San Nicolás de Aarhus se nos relatan algunos milagros acontecidos poco después de su muerte en 1180. En relación con la vida de este santo se narra que un mudo de nacimiento visitó en esta época Santiago de Compostela ${ }^{7}$.

El primer peregrino danés conocido a Santiago del siglo XIII es Andrés de Slagelse, conocido comúnmente en esta ciudad del oeste de la isla de Selandia como «San» Andrés (Hellig Anders). Este Andrés, que exitió en realidad pero del que no consta en ningún lugar que fuera canonizado, ejerció su misión sacerdotal en la iglesia de San Pedro de la misma ciudad y murí en 1205. Además de otros hechos maravillosos que se cuentan de él, parece el más extraordinario el viaje que efectuó a Tierra Santa. Una vez llegado allí con sus compañeros, y de haber celebrado la misa junto al sepulcro del Señor, llegó al puerto y se encontró con que sus compañeros habían ya zarpado hacia Dinamarca. Cay6 en oración y tuvo una visión: se le aparecí́ un caballo blanco y el que lo montaba le dijo: «sube, que yo te llevaré». Así lo hizo y emprendió el viaje con él por los aires. Primero a Santiago de Compostela y luego a Slagelse. Cuando volvió en sí se encontró sobre una colina que hay junto a Slagelse y oyó a unos pastores que hablaban danés. Cuando les preguntó dónde estaba y qué hora era, le respondieron que estaba junto a Slagelse y que era tarde ya del día de Pascua. Sucedió, por lo tanto, que el mismo día celebró misa en Jerusalén y las vísperas en Santiago. Como se encuentra una antífona, versículo y oración de este "santo», parece lógico suponer que nuestro Andrés fue, por lo menos durante algún tiempo, objeto de culto popular en la iglesia de San Pedro de Slagelse. También existía un misal en la citada iglesia en el que figuraba nuestro Andrés y que, por consiguiente, este culto contaba por lo menos con la tácita aprobación de la mencionada iglesia ${ }^{8}$. Todos los estudiosos de San Andrés de Slagelse coinciden en la fecha de su muerte: 1205. Todos los otros detalles sobre este maraviloso viaje son pura hipótesis 9 .

Se han mencionado varios casos de «commutatio voti», es decir la autorización dada a un peregrino o peregrina para cambiar un voto por otro, o también por una suma de dinero o por el ejercicio de una práctica religiosa, cosa frecuente en las fuentes históricas escandinavas. El primer caso conocido de esta «commutatio» en relación con Santiago de Compostela de Dinamarca data

\footnotetext{
7 Scriptores Rerum Danicarum, V, p. 306.

8 V. ALMAZAN, "Unha pelerinaxe aérea ao Xacobe de Galicia no século XIII", Grial, p. 82 (1983) pp. 399-409.

9 M. Cl. GeRTz, Vite Sanctorum Danorum, Copenhague, 1908, pp. 395, 412 y 416.
} 
del 27 de febrero de 1224, cuando el obispo de Roskilde da una autorización para que se cambie el voto de ir a Compostela por Tierra Santa ${ }^{10}$.

También en algunos testamentos se habla de Santiago de Compostela. El más antiguo conocido fue escrito en 1292. Se trata de una viuda danesa llamada Gyde Karlse que deja una suma de dinero para los peregrinos a varios santuarios, entre los que leemos «Item ad Sanctum Iacobum tres solidos sterlingonum»"

El primer peregrino danés conocido que fue a Santiago del siglo XIV es un tal Jonas, del que se conserva una lápida que se hallaba en la iglesia de Sorø. En 1344, durante el reinado de Valdemar IV, hubo un intercambio de correspondencia entre los obispos de Uppsala y Nídaros. En una de estas cartas escribe el obispo sueco que para las ofrendas prometidas a algún santo, como por ejemplo a Santiago de Compostela, no es preciso mandar ese dinero al santuario gallego, ya que ese santo se venera en otros muchos lugares ${ }^{12}$.

El 28 de noviembre de 1345 el prior del convento de los padres dominicos de Lund dispensa a una mujer llamada Margarita af Markie, del voto que había hecho de peregrinar a Santiago de Compostela ${ }^{13}$.

También del siglo XV conocemos varios casos de «commutatio voti».

Un caso interesante de este siglo es el del danés Erik Markvardsen de fines de este siglo. Según un documento del 24 de julio de 1493, firmado por el obispo Juan de Bergen, un joven ciudadano de la provincia danesa de Ribe mató a un tío suyo en un arrebato de cólera. En penitencia fue obligado a caminar, desnudo y a golpes de bastón, hasta Santiago de Compostela con cadenas que le llegaban hasta los pies, y las manos atadas al cuello. Durante tan penosa peregrinación le estaba prohibido pedir limosna, y tenía que mantenerse de la caridad de los fieles que lo veían. Este obispo concede cuarenta días de indulgencia a todos los que ayuden al pobre desgraciado ${ }^{14}$. No sabemos, sin embargo, si tan cruel sentencia fue realizada.

El último siglo de las peregrinaciones danesas a Galicia se desarrolla de manera semejante a los precedentes. La Reforma, sin embargo, se esparce rápidamente por el país y no tengo ninguna prueba de que haya habido ninguna posterior al año 1526, hasta épocas más recientes.

Numerosos son, sin embargo, los testimonios del primer tercio de este siglo: el libro de cuentas de la reina Cristina (1496-1521), algunos breves de los reyes y de varios obispos dictando normas para los peregrinos a Santiago, documentos co-

\footnotetext{
10 Vite Sanctorum Danorum, Ed. M. Cl. GERTZ, Copenhague, 1908-1912. p. 443.

I Diplomatarium Danicum, 2, IV, p. 49.

12 P. F. SUHM, Historie af Danmark, t. XII, Copenhague, 1826 p. 115.

13 Acta Pontificum Danica, Copenhague, 1904, t. I, $n^{\circ} 333$.

14 Diplomatarium Norvegicum, XVII, p. 127.

$\mathrm{I}^{\text {er }}$ Congreso de Historia de la Iglesia Hispania Sacra 51 (1999)
} 
merciales que regulan disposiciones de barcos que llevan peregrinos a Santiago, votos documentados de peregrinación a Santiago, cartas de recomendación a las autoridades por donde van a pasar peregrinos daneses a Santiago, etc. La lista de contactos entre Dinamarca y España con motivos de la peregrinación a Santiago terminan en la época de la Reforma con un hombre que vivió en Dinamarca y España: Santiago el Danés (Jacobus Dacianus). En los últimos veinte años, y gracias al historiador danés Jørgen Nybo Rasmussen, sabemos de este franciscano extraordinario. Santiago el Danés (1484-1566) fue el último provincial franciscano de la provincia de Dacia (como llamaban los franciscanos y dominicos al territorio formado por Dinamarca, Suecia y Noruega). Al triunfar la Reforma en Dinamarca pasó este franciscano a Alemania, y más tarde se fue a España, saliendo luego a Sevilla desde donde salió para Veracnuz para servir de misionero en México en 1542. Allí aprendió varias lenguas en Michoacán. Tomó parte en varias polémicas sobre la ordenación de indígenas al sacerdocio. Falleció en su convento de Tarecuato en olor de santidad. Sobre este danés, 'el primero que llegó a México han escrito otros autores, además de Nybo Rasmussen ${ }^{15}$.

En el reino de Dinamarca existen, o han existido, 24 iglesias o capillas y 4 fuentes dedicadas a Santiago el Mayor. Algunas de ellas han desaparecido debido a varias razones: simplemente fueron destruidas, otras destrozadas por las inclemencias del tiempo: hundimiento en la arena o maremotos en la costa, o simplemente abandono total.

Estas iglesias o capillas son:

Roskilde (Sankt Ib). S6lo queda la nave central (1291).

Hven (Sankt Ibb). De principios del siglo XII.

Varde. Siglo XIV.

Horsens. Santiago, siglo XIII, hoy del Salvador. Nombre cambiado en 1796 por el obispo Janson porque «ya no debemos llamar Santiago a esta iglesia, sino que en lugar de este nombre católico, recibirá un nombre más apropiado: la Iglesia del Salvador» 16.

Måløv. Siglo XII.

Slesvig. A partir del siglo XI, hoy desaparecida.

Søderbrårup. Siglo XII. Se conserva un sello de esta parroquia en el Museo Nacinal de Copenhague.

Moldenit. Fin del siglo XII. Se conserva el sello.

15 Bruder Jakob, der Däne OFM als Verteidiger der religiösen Gleichberechtigung der Indianer in Mexiko im 16. Jahrhundert. Wiesbaden, 1974; ib., Broder Jakob den Danske, kong Christian II's yngre broder. Odense, 1986. También existe una novela histórica del conocido autor danés Henrik Stangerup Broder Jakob, Copenhague, 1991, traducida también al francés. El capítulo "El camino a Santiago de Compostela' ocupa las pp. 103-125.

16 Hanne Jönsson, Gud til AEre Kiercken til Zirat. Peder Jønsson Koldings pradikestol i Vor Frelsens Kirke: Horsens 1670, Horsens, 1987.

$\mathrm{I}^{\mathrm{er}}$ Congreso de Historia de la Iglesia Hispania Sacra 51 (1999) 


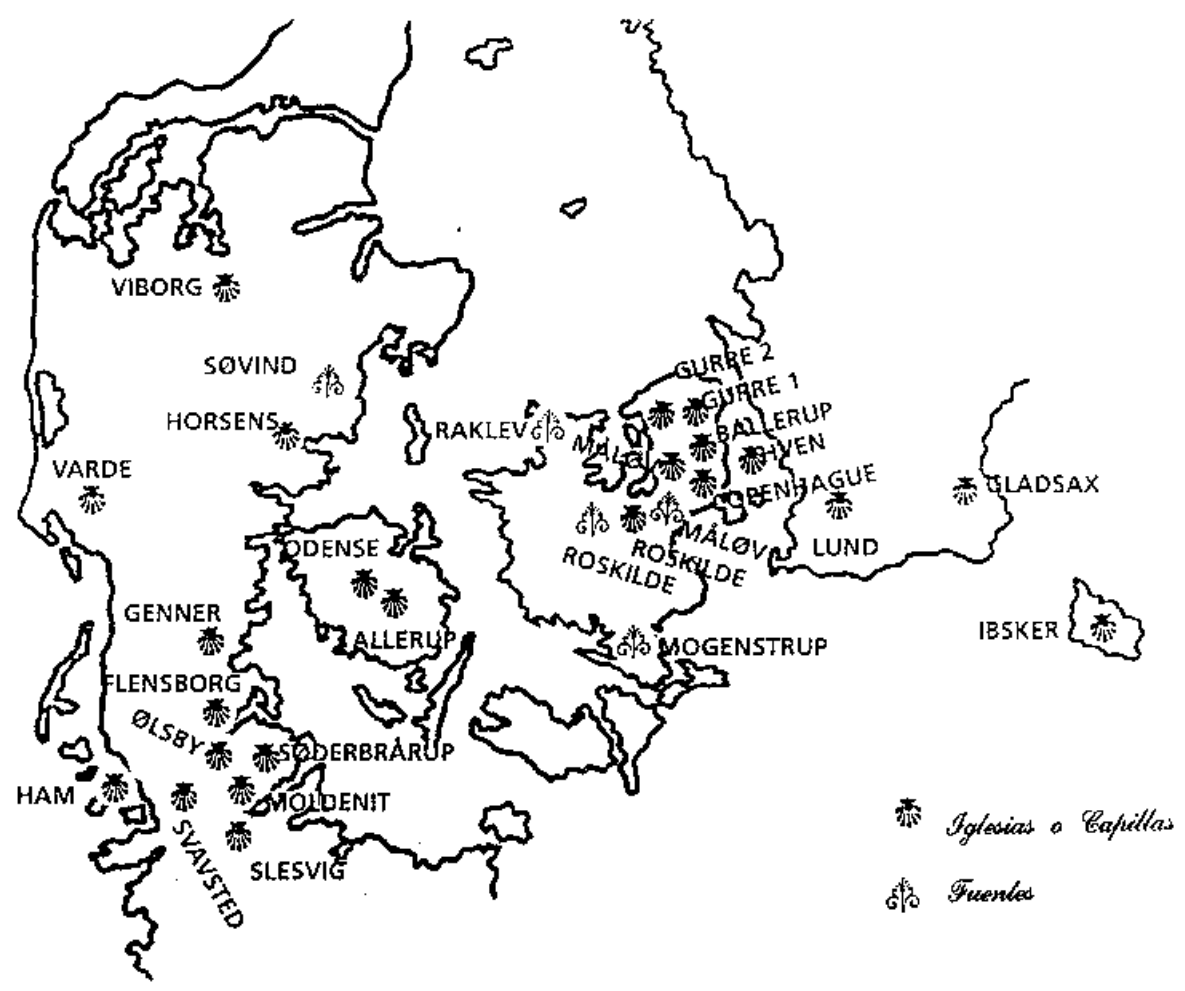

$r^{\text {sv }}$ Congreso de Historia de la Iglesia Hispania Sacra 51 (1999) 
Ballerup. Probablemente siglo XIII. Esta es probablemente la iglesia de Santiago más hermosa de Dinamarca, a unos $20 \mathrm{~km}$ al oeste de Copenhague. Esta ciudad ha conservado la tradición de tener una cofradía de Santiago, y además de nombrar cada año a un personaje ilustre de la ciudad como «Santiago del año».

Svabsted. De 1200. Torre separada de la iglesia (hay muchas así en Dinamarca) con un magnífico retablo.

$\emptyset$ lsby. Siglo XIII. Según una antigua tradición pasó por aquí Santa Brígida de Suecia en su peregrinación a Santiago en 1342. De esta tradición se conservan dos magníficos gobelinos: de Santiago y de Santa Brígida.

Viborg (Sankt Ib). Fin del siglo XIII. En el inicio del único camino de Santiago danés documentado. La iglesia fue destruida por ordel del rey Cristián IV. El nombre de Santiago ha quedado todavía hoy en la puerta norte de la muralla, en el nombre de la calle principal y en un hogar de ancianos.

Lund. Siglo XIV. La iglesia ha desaparecido, pero todavía existe «el barrio de Santiago» y un aparcamiento "Santiago» en el lugar exacto donde se encontraba la iglesia de Santiago.

Gladsax. Principios del siglo XIV. Hoy parroquia luterana con preciosas pinturas murales de la época anterior a la Reforma.

Allerup. Siglo XIV. A pocos kms. de Odense, con un precioso retablo.

Gurre. Siglo XIV. Hoy se pueden contemplar las ruinas.

Ibsker. Siglo XIV. En la isla de Bornholm, ya en el Mar Báltico. El único topónimo donde perdura completo el nombre de Santiago (Ibsker en el dialecto local quiere decir «iglesia de Santiago»).

Genner. Siglo XV. Capilla desaparecida, documentada sólo en mapas antiguos, no lejos de la actual frontera con Alemania.

Flensborg. Siglo XIII. Capilla que existía en la iglesia de Santa María, en la ciudad fronteriza boy en día.

Ham. Siglo XIV. Se conserva el sello de esta parroquia en la isla de Norstrand. En 1634 fue tragada por un violento maremoto que se tragó un tercio de la población.

Skagen. Principios del siglo XVI. Capilla en la punta más septentrional de la península de Jutlandia, tragada por la arena pero documentada en mapas antiguos.

Copenhague. Siglo XIX. En un barrio que pertenecía a la parroquia de San Juan y que al formar una nueva se decidió darle el nombre del hermano de San Juan por las relaciones fraternales con aquella parroquia.

Odense. Siglo XIX. Hasta 1968 perteneció a la Iglesia Metodista danesa, pasando entonces a la Iglesia Apostólica de Dinamarca.

Tíkøb. Siglo XX. Para la construcción de esta glesia se utilizaron las piedras de la antigua iglesia de Santiago de Gurre, hoy en ruinas.

De las fuentes de Santiago: Mogenstrup, Måløv, Roskilde, Søvind y Raklev, sólo la de Roskilde sigue dando agua y puede verse claramente en el jardín de la iglesia de Santiago de Roskilde.

El papel que desempeñaron las cofradías o gremios daneses en la Edad Media es de gran importancia en la vida cultural de la época. Gracias al investigador danés C. Nyrop disponemos hoy de un buen conocimiento del origen $\mathrm{e}$ 
historia de estos gremios ${ }^{17}$. Al final de la Edad Media los gremios o cofradías de Dinamarca eran numerosas. y ejercían gran influencia en la sociedad. Ś́lo en la ciudad de Ribe, que no era muy grande, existían 21 gremios. Con el advenimiento de la Reforma terminaron estos gremios.

Los primeros estatutos de dichos gremios en los que se menciona una peregrinación (en la isla de Lolland) a Santiago de Compostela datan de 1388, y están escritos en latín. Siguen otros de otras varias ciudades, igualmente escritos en latín, y luego en danés. Por ejemplo en los de Santa Gertrudis, en el sur de Copenhague, leemos en el artículo 7: «Los que quieran ir en peregrinación a Aquisgrán reciben tres marcos de Lübeck, así como los que se dirijan a San Olaf en Trondheim, pero los que vayan a Roma o a Santiago de Compostela recibirán cinco» ${ }^{18}$.

En 1476 se redactan los estatutos del gremio de zapateros de Køge. El patrono de este gremio era Santiago. No son raros los gremios, sobre todo de zapateros, que tuvieron a Santiago como patrón. Cumple a este respecto no olvidar lo que dice aquella cantiga:

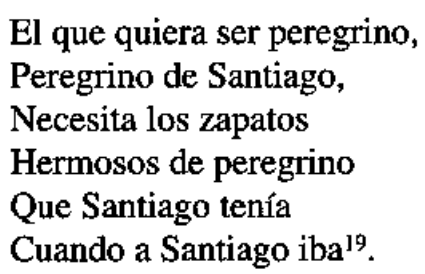

De los gremios de varias ciudades leemos la ayuda que hay que prestar a los peregrinos a Santiago. También se conservan varios sellos de gremios daneses que ilustran la presencia del apóstol Santiago.

Además de la presencia de Santiago en varios sellos de los gremios medievales daneses, son numerosísimos aquellos en los que aparece el Apóstol en sellos de familias nobles y de miembros del clero.

\section{LA VENERA JACOBEA EN DINAMARCA}

Dos investigadores se han destacado en los últimos años por los estudios, catálogos y descripciones exactas de las veneras jacobeas auténticas: el alemán

17 C. NYROP, Danmarks Gilde- og Lavskraaer fra Middelalderen, Copenhague, 1899-1904.

18 Idem., p. 565.

19 K. StrkeluJ, "Colección de las canciones eslovenas", Cuadernos de Estudios Gallegos LX (1848) p. 74 .

$\mathrm{I}^{\mathrm{er}}$ Congreso de Historia de la Iglesia Hispania Sacra 51 (1999) 
Kurt Köster ${ }^{20}$ y el sueco Lars Andersson ${ }^{21}$. De estos trabajos se deduce que las primeras veneras de Santiago que se han encontrado datan de los siglos XII y XIII. De las 180 veneras de peregrino estudiadas por Köster, 140 procedían de tumbas. Andersson hace una lista de 122, descubiertas en los países escandinavos. Como este investigador sueco nos indica el lugar exacto de procedencia, es fácil determinar las que pertenecían al antiguo reino de Dinamarca que son 46. A éstas hay que añadir 54 en la provincia de Escania, una en Småland y 11 en Schleswig, es decir un total de 112 veneras auténticas encontradas en el antiguo reino de Dinamarca. A estas 112 veneras se suman las que se han encontrado más recientemente en una excavación efectuada en la iglesia de San Nicolás de la ciudad de Holbæk, al oeste de Copenhague. Todas ellas llevan las dos perforaciones características. De esto informa Hanne Dahlerup $\mathrm{Koch}^{22}$. Con estas 122 veneras se situa Dinamarca a la cabeza de todos los países europeos en cuanto a número de veneras halladas.

La venera como símbolo es, por supuesto, mucho más antigua que el culto al apóstol Santiago. Sin embargo, su aparición en la iconografía cristiana se debe al florecimiento del culto a Santiago ${ }^{23}$. En los países escandinavos la representación más antigua data de mediados del siglo $\mathrm{XI}^{24}$. Entre los antiguos almanaques confeccionados en tablillas de madera del siglo XV en los que las festividades se marcan con un símbolo ya encontramos una venera para indicar el 25 de julio.

En la heráldica danesa la venera está extendidísima. En Europa existen aproximadamente 20.000 escudos con una o varias veneras ${ }^{25}$. Del 25 de noviembre de 1983 hasta el 15 de enero de 1984 se celebró una exposición en el Museo de Industria de Copenhague en el que se puso de relieve la importancia de la venera de Santiago en la heráldica y en los caminos de peregrinación, tanto es así que en la lengua danesa recibeun un nombre especial: Ibskallen (concha de Santiago). Numerosas son las iglesias que llevan en sus escudos la venera de Santiago. En un estudio sobre la sigilografía danesa de los siglos XV-XVII se cuentan 116 sellos en las que no sólo distinguimos una venera, sino que ésta es parte esencial del mismo ${ }^{26}$. Es evidente que el motivo de la

\footnotetext{
20 Pilgerzeichen und Pilgermuscheln von mittelalterlichen Santiagostraßen, Neumünster, 1983.

21 Pilgrimsmdrken och vallfart. Medeltida pilgrimskultur i Skandinovien, Estocolmo, 1989.

22 "Jakobspilgrimme fra Holbæk", Fra Holbcek Amt, 1990, pp. 11-26.

23 Sobre este tema v. Christopher HOHLER, "The badge of Santiago", The Scallop. Studies of a Shell and its influences on Humankind. Londres (circulación particular), 1957, pp. 49-70.

24 V. para Dinamarca Helge SøGAARD, "Pilgrimsmärken", Kulturhistorisk Leksikon for Nordisk Middelalder, XIII, pp. 314-320.

25 S. TITO ACHEN, "Muslingeskallen i heraldiken", Konkylien og Mennesket, Copenhague, 1983 84, p. 69.

26 P.B. GRANDJEAN, Dansk Heraldik, Copenhague, 1919, p. 140.
} 
presencia de esta venera en los escudos de las familias puede también ser debido a razones diferentes a una peregrinación. El motivo puede ser que una persona se llamara Santiago, o se apellidara Jakobsen o Ibsen, o tal vez que naciera el 25 de julio o que tenía una devoción especial a Santiago o que quería indicar que su vida fue un continuo peregrinar, no necesariamente a Santiago de Compostela.

En Dinamarca los sellos de las familias nobles empezaron a entrar en uso en el siglo XIII, culminando éste en el siglo XV.

Como ocurre con los sellos o blasones de personas, no siempe habrá que atribuir la presencia de la venera a una peregrinación a Santiago. Sin embargo, la ciudad de Ballerup, por ejemplo, ostenta en su escudo dos veneras y los manantiales que dejan correr sus aguas. Este escudo fue creado por el heraldista Grandjean en 1935 e indican las dos iglesias de Santiago que existen en esa ciudad, y las aguas de la fuente que se encontraba en dicha ciudad.

Entre los tesoros más preciados del arte danés destaca la extraordinaria colección de pinturas murales sobre cal de iglesias repartidas por todo el país en número asombroso, desde el siglo XI hasta la Reforma, e incluso después, en una increíble manifestación de la creatividad artística del hombre. Para el estudio de la iconografía el examen de representaciones del apóstol Santiago se revela como un tema de gran interés. Las pinturas de Santiago catalogadas son de muy diverso valor. El apóstol se nos aparece aquí casi siempre en su atavio de peregrino, y en forma destacada, se cuentan más de cincuenta, destacando una de hacia 1443 en la iglesia de Santiago de Ballerup.

También en la escultura danesa el apóstol Santiago no es una figura rara, incluso como figura independiente. Casi siempre se nos presenta de pie, aunque también sentado. Casi todas estas estatuas son de piedra o de madera, pero existen algunas, probablemente traidas por algún peregrino, confeccionadas en azabache.

Santiago de niño es una figura iconográfica frecuente en la escultura danesa. Esta aparición está siempre relacionada con el culto a Santa Ana, muy extendido en el culto de la Europa septentrional del siglo XV. Estas apariciones las encontramos no sólo en la escultura, sino también en la pintura.

En la orfebrería danesa encontramos igualmente huellas de este culto jacobeo. Igualmente en cálices. Al pie de estos aparece el apóstol Santiago, principalmente en aquellos que pertenecieron a alguna iglesia de Santiago, como en Viborg o Moldenit.

En las letras danesas la presencia del apóstol Santiago es también frecuente. Primeramente el nombre de varón Jakob o $l b$ cuenta entre los más comunes en

$\mathrm{I}^{\mathrm{er}}$ Congreso de Historia de la Iglesia Hispania Sacra 51 (1999) 
la Edad Media, existiendo de este nombre 91 formas diferentes ${ }^{27}$. De estos nombres se formaron más tarde los apellidos Jacobsen, Ibsen y semejantes que cuentan todavía hoy entre los más frecuentes en las guías telefónicas de cualquier ciudad danesa o lista de apellidos de cualquier índole.

El nombre de Santiago no es exclusivo de nombres de personas. Entre los nombres de lugar daneses existe un gran número de ellos que contienen la raiz $J a k o b-, I b-$, Jeppes-, Jeps- y otras semejantes, todas derivadas de «Santiago».

En las canciones populares danesas España aparece en algunas de ellas. Sin embargo, la canción popular danesa más popular y extendida dentro de la temática jacobea es la que lleva por título Den helige Jakob (Santiago). Esta canción es conocida no sólo en Dinamarca, sino que también existen versiones de la misma con diferentes variantes en Noruega (4 versiones), Suecia, Finlandia (en la parte finlandesa de habla sueca), y en las Islas Feroé. De estas islas se conocen cinco versiones diferentes que tienen la particularidad de ser bailadas en lo que constituye una manifestación típica del folklore de estas islas.

En un estudio publicado en $1971^{28}$ se preguntaba la autora si la canción o romance viene de Dinamarca o si la versión noruega tiene otro origen, y cree que la canción tuvo en los países escandinavos una evolución paralela a la de las historias islandesas de los apóstoles. No hay que olvidar que las versiones feroesas son las más interesantes, originales y de mayor belleza. Como estas islas, a pesar de una fuerte autonomía, siguen siendo parte del reino de Dinamarca, presentaré aquí una traducción libre íntegra de este romance:

Santiago implora la ayuda del Señor

para que lo deje viajar.

«Quiero cristianizar el país de Galicia».

Cuando salió, el bosque resplandecía.

« Cómo quieres tú ganar cristianos

si no tienes barco en que ir?»

«Grande es tu ignorancia.

Busca un barco en el que ir.

Ve a la orilla del mar.

Allí verás una gran piedra».

Santiago lleva su libro en la mano,

Y allí va, a la orilla del mar.

Santiago planta una cruz en la piedra, no tarda en navegar.

27 R. HORNBY, Danmarks gamle Personnavne, Copenhague, 1936, cols. pp. 587-599.

28 Ådel Gjøstein Blom, Ballader og Legender fra Norsk Middelalderdikzning, Oslo, 1971. 
La piedra flota en el mar.

$Y$ así va hacia Galicia.

La piedra navega con tanta maravilla que pronto cubre quinientas millas.

He aquí un muchacho que dice:

"Mira una piedra que viene con un hombre sentado en ella».

El rey de Galicia coge su hacha.

Allí va, a la orilla del mar.

"Oye, Santiago, te hablo a ti:

¿Qué buscas en mi país?»

«En mi piedra vengo a decirte que mi Dios es mejor que el tuyo".

«QQue tu Dios es superior al mío?

El mío bebe a diario aguamiel y'vino.

«Entonces mi Dios es superior al tuyo, porque el mío del agua hace vino".

«El mío de la tierra hace pan,

Y da vida al que está muerto».

«Si haces que resucite mi hijo, entonces creeré en tu Dios».

«Que vuelva con honor y pelo

el que desapareció hace quince años».

«Que vuelva a mí con halcón y con su perro

el que desapareció en el fondo del man».

«Que vuelva a mí, con honor y pelo

el que no conoció sus mejores años».

Santiago con su libro le dice que no es fácil hacer que vuelva.

Santiago calla un momento e invoca al fondo de la tierra.

«He aquí, con honor y pelo el que desapareció hace quince años».

«Aquí tienes, con halcón y perro

el que desapareció en el fondo del mar».

«He aquí, con honor y pelo

el que no conoció sus mejores años".

«Escucha, hijo, tan apuesto y hermoso: ¿de qué te ha servido el viaje?"

$I^{\text {er }}$ Congreso de Historia de la Iglesia Hispania Sacra 51 (1999) 
«No tiene gozo en otro lugar

el que está en ajeno hogar».

«La mujer que odia a su marido

No sale del huerto de las serpientes».

«La mujer que mata a su hijo querido

Va ceñida de una espada venenosa».

«El comerciante que acumula riquezas

ladra allí como una serpiente».

«Esos hombres tan ocupados y crueles

ladran allí en el huerto de las serpientes».

«El mismo corregidor con su ancho gorro

En el infierno sigue exigiendo impuestos".

«Ahora está mi hijo conmigo,

ahora quiero creer en tu Dios».

Esto hizo Santiago, mientras alli estuvo.

Al rey bautiza y a todo su ejército con él.

Sea cual fuere la versión más antigua (probablemente noruego-islandesa) es evidente que este romance es uno de los más bellos que nos haya dejado la cultura nórdica: una mezcla de elementos tomados de la leyenda jacbea con motivos de la mitología nórdica. La música, al ritmo en que se baila este romance en las Islas Feroe, fue publicada por primera vez en $1908^{29}$.

La última parte de esta comunicación quisiera dedicarla a describir brevemente la presencia del apóstol Santiago en la literatura carolingia danesa de la Edad Media.

Hacia 1480 una serie de sagas de tema carolingio fue traducida del islandés al danés bajo el título de Crónica de Carlomagno, dada a conocer por el investigador danés Poul Lindegård Hjorth ${ }^{30}$. Me llevaría demasiado lejos analizar esta obra. Baste decir que se deriva en general de la Historia Karoli Magni et Rotholandi, llamada comunmente Pseudo-Turpín. En esta Crónica danesa encontraremos toda una serie de elementos de la leyenda jacobea que arraigaron profundamente en la tradición oral y escrita de la cultura danesa.

Hay todavía otros temas jacobeos, particularmente el origen de la bandera danesa, la más antigua de las existentes, que guarda estrecha relación con temas jacobeos.

29 Hjalmar THUREN, Folkesangen paa Farøerne, Copenhague, 1908, p. 138.

30 Karl Magnus' Krønike, Copenhague, 1960, seguida de un estudio filológico del mismo en 1965.

$I^{\text {er }}$ Congreso de Historia de la Iglesia Hispania Sacra 51 (1999) 